\title{
Land use/land cover change detection through temporal imageries and its implications in water induced disaster in Triyuga watershed, east Nepal
}

\author{
Rabindra Choudhary ${ }^{1}$ and ${ }^{*}$ Dinesh Pathak ${ }^{2}$ \\ ${ }^{1}$ Institute of Engineering, Tribhuvan University, Lalitpur, Nepal \\ ${ }^{2}$ Central Department of Geology, Geodisaster Research Center, Tribhuvan University, Kathmandu, Nepal \\ (*Email:dpathaktu@gmail.com)
}

\begin{abstract}
Land use and land cover is an important component in understanding the interactions of the human activities with the environment. Land use planning are widely recognized as key non-structural risk mitigation measures. In the present study, decadal land use changes in the Triyuga watershed has been assessed for the period between 1980 and 2015. Satellite images of Landsat (ETM, TM and OLI) have been used to prepare land use maps for respective period. The relationship between disaster loss, land use and meteorological factor (rainfall) has been evaluated. Significant correlation between the parameters has been obtained.
\end{abstract}

Keywords: Land use change, temporal images, water induced disaster, land degradation, Triyuga watershed

Received: 27 January 2016

Revision received: 3 June 2016

\section{INTRODUCTION}

Land cover and land use change means changes in structure and function (qualitative) and change in the area extent (quantitative) of given type of land use or cover. Two types of land use change can be distinguished. First one is conversion, i.e. change from one cover type to another and another one is modification, which means alteration of structure or function without a complete change from one type to another, (Briassoulis 2000). Land cover change occurs as a result of natural process such as climatic variation, volcanic eruption, changes in the river channel or sea level, etc. Most of the land cover changes of the present and recent past are due to human actions i.e., to use the land for production or settlement (Briassoulis 2000).

Advances in remote sensing technology enables the scientists to identify on-going land cover change processes and their locations. One of the main challenges of this technology is to ensure that a change is not a result of short-term variations in land cover. For instance, in agricultural land use, which is systematically linked through seasonal-temporal interactions, the land might be associated with a sequence of covers through a year, as a vegetated land (vegetation), barren land and inundated land (water); meanwhile, the actual change is when the land is converted in to built-up or other uses. In reality, land cover change is more complicated since it can be also categorized into three types and mechanisms, namely, seasonal change, driven by annual temperature and rainfall interactions on vegetation phenomenology; gradual change, caused by inter annual climate variability or on land management; and abrupt change, caused by disturbances such as deforestation, urbanization, floods, and fires (Setiawan and Yoshino 2012).
Change detection is the process of identifying differences in the state of an object or phenomenon by observing it at different times. A variety of digital change detection techniques has been developed in the past three decades. Basically, the different algorithms can be grouped into the following categories: algebra (differencing, ratioing, and regression), change vector analysis, transformation, classification and hybrid method (Nori et al. 2008).

The land cover change detection problem is essentially one of the detecting process when the land cover at a given location has been converted from one type to another. Example include the conversion of forested land to barren land, grasslands to golf courses and farmland to housing developments. There are number of factors that make this a challenging problem (Boriah 2008). Land use planning, management and in some instances land conservation or rehabilitation reduce our vulnerability to natural hazards and disaster risks (UN/ISDR 2004). Many studies on land use/land cover mapping have been done (Holbrook and Tudor 1993; Singh and Dubey 2012; Bandyopadhyay et al. 2014; Prawasi et al. 2015).

The main objective of the present study is to analyze the land use/land cover changes in Triyuga watershed during the last four decades and to correlate with the losses due to geodisaster (landslide and flood) in the respective period and also to correlate the disaster losses with the climatic factor (rainfall).

\section{STUDY AREA}

Geographically, Triyuga watershed is located between $26^{\circ} 45^{\prime}$ to $26^{\circ} 51^{\prime}$ north latitude and $87^{\circ} 6^{\prime}$ to $86^{\circ} 34^{\prime}$ east longitude (Fig. 1). It is spread over Udaypur and Saptari districts and small 


\section{Choudhary and Pathak}

portion of Sunsari district of east Nepal. The elevation ranges from $120 \mathrm{~m}$ to $2,000 \mathrm{~m}$. The study area covers total of $992 \mathrm{~km}^{2}$.

Triyuga watershed lies in the Churia range, which is young mountain region and composed of less compacted sedimentary rocks such as mudstone, sandstone, siltstone, shale. and conglomerates. Soils are mostly formed on sedimentary rocks with shallow depth and are coarse textured. Steep slopes and weakly consolidation of different layers is prone to severe surface erosion. Because of intense rainfall during monsoon, steep slopes and high erosion, vulnerability of soils, gullies and degraded lands are quite common in areas that are devoid of vegetative cover.

\section{MATERIALS AND METHODS}

Multi temporal satellite data set observed by Landsat (4-5)-Thematic Mapper (TM), Landsat 7- Enhanced Thematic Mapper (ETM ${ }^{+}$, Landsat 8-, Operational Land Imager (OLI) and Topographic Map of Department of Survey were used for the analysis. TM, $\mathrm{ETM}^{+}$and OLI are the optical sensors which has 7, 8 and 11 multi-spectral bands between visible and infrared radiations (Table 1). Landsat imagery is relatively high resolution earth observation data that is acquired through sensors on one of the NASA Landsat satellites. The satellite sensors acquire high integrity images of the planet surface in a systematic fashion. Users take this imagery and use it to determine the health and type of vegetation, amount of built surfaces, success of agriculture, or apply it for a myriad other uses. The satellite images for 1987, 1997 and 2007 consist of seven spectral bands with spatial resolution 30 meters for bands 1 to 5 and 7 . The spatial resolution for band 6 (thermal infrared) is $120 \mathrm{~m}$, but is resampled to 30 meter pixels. Satellite image for 2015 is Landsat 8 Operational Land Imager images which consists of nine spectral bands with a spatial resolution of 30 meters for bands 1 to 7 and 9 . New band (ultra-blue) is useful for coastal and aerosol studies. New band 9 is useful for cirrus cloud detection. The resolution for band 8 (panchromatic) is 15 meters. Thermal bands 10 and 11 are useful in providing more accurate surface temperatures and stores data at $100 \mathrm{~m}$ resolution. The Landsat satellite imageries used in this study are shown in Fig. 2.

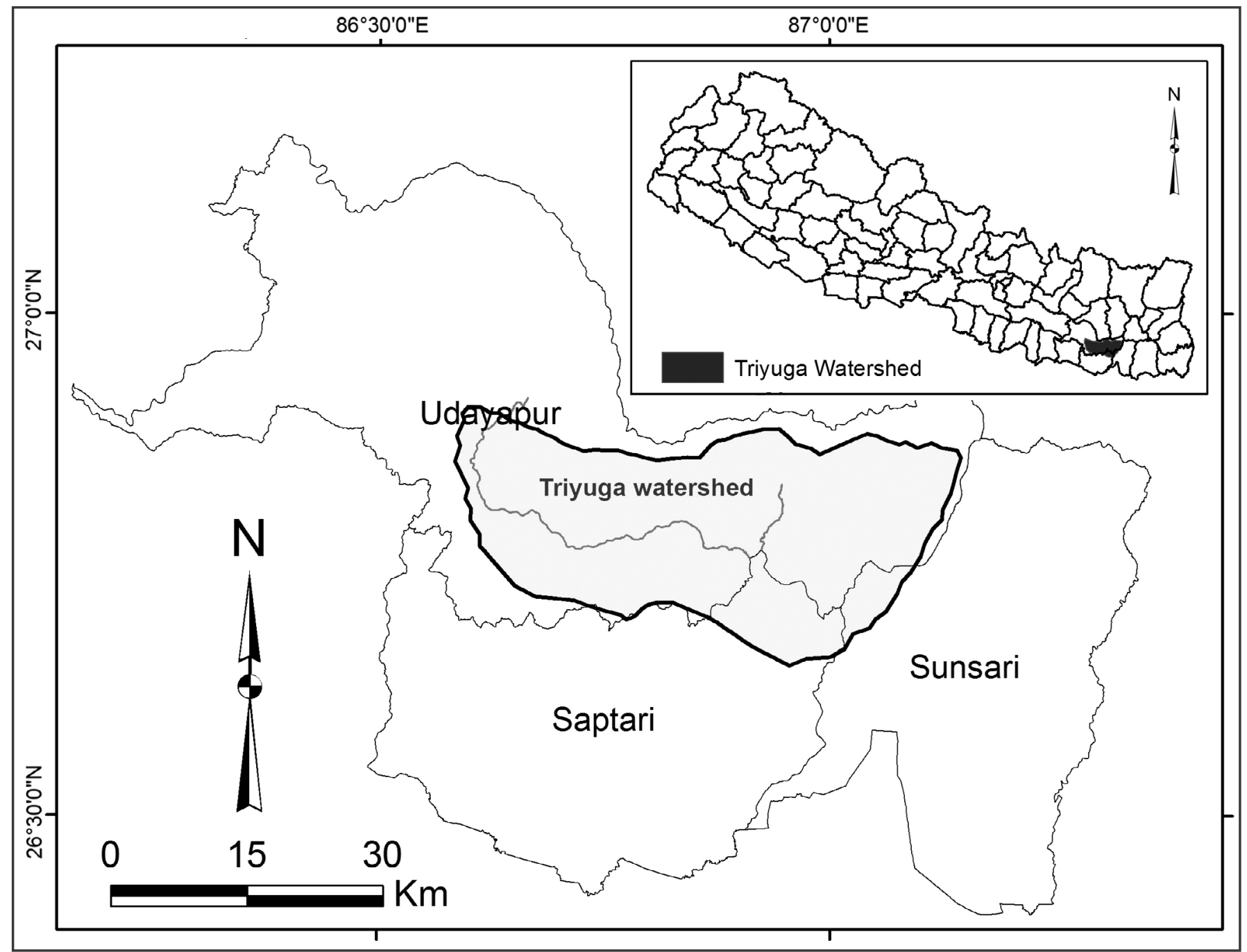

Fig. 1: Location of the Triyuga watershed. 
Land Use/Land Cover Change detection through temporal imageries and its implications in water induced disaster

Table 1: Landsat satellite sensor specification (GLCF 2004).

\begin{tabular}{|l|l|l|l|l|l|}
\hline Satellite & Sensor & Swath (km) & Scene Size (km) & Altitude (km) & Revisit (days) \\
\hline L 1-5 & MSS & 180 & $180 \times 170$ & 917 & 18 \\
\hline L 4-5 & TM & 185 & $170 \times 183$ & 705 & 18 \\
\hline L 7 & ETM+ & 185 & $170 \times 183$ & 705 & 16 \\
\hline L 8 & OLI & 185 & $170 \times 185$ & 705 & 16 \\
\hline
\end{tabular}
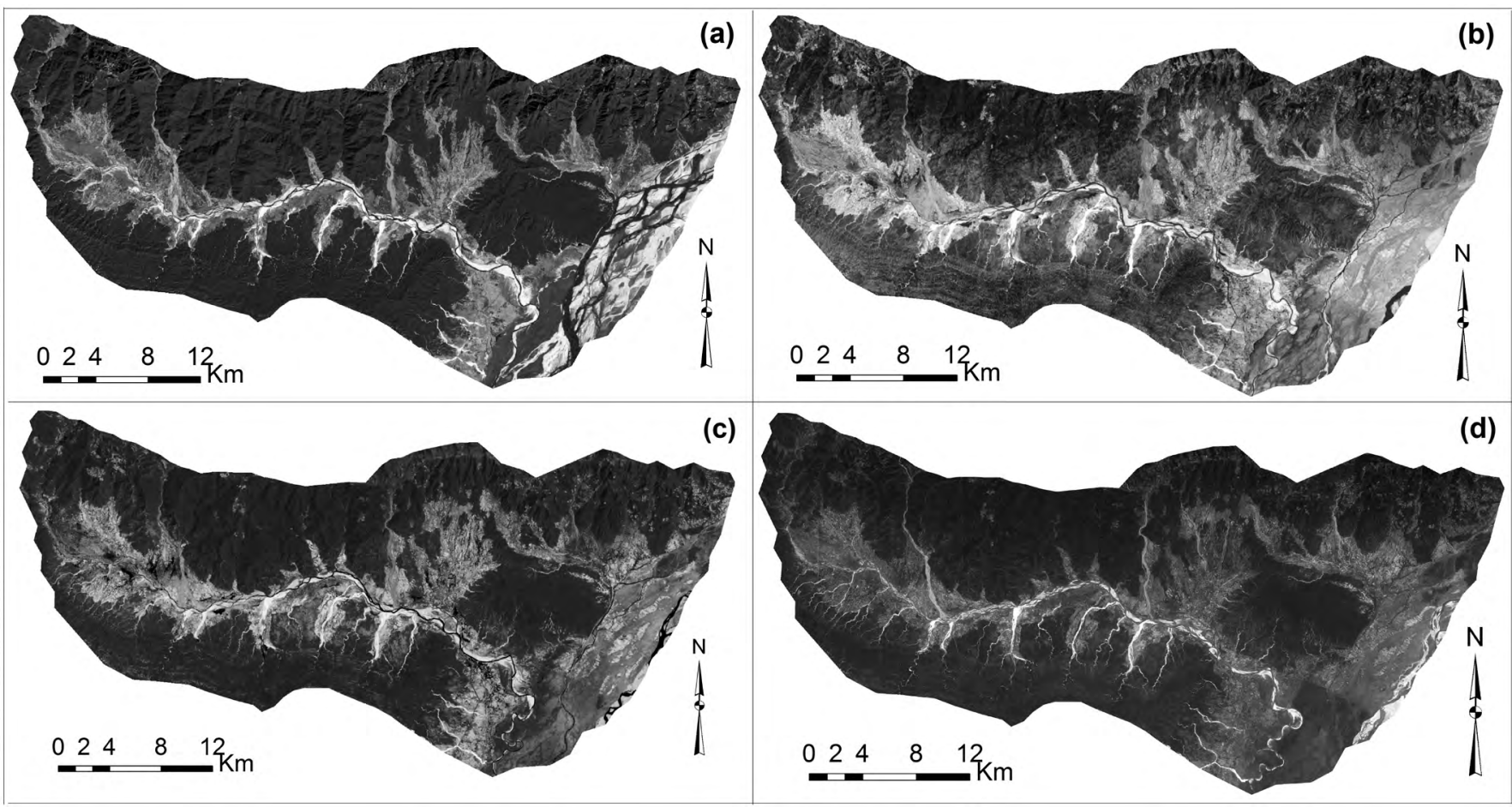

Fig. 2: Temporal satellite imageries of the study area - (a) 1987, (b) 1997, (c), 2007 and (d) 2015.

The image resolution is $30 \mathrm{~m} \times 30 \mathrm{~m}$ (pixel size). Digital Land use/ land cover classification through supervised classification method, based on the field knowledge is employed to perform the classification. Arc GIS platform provides very effective platform for extracting the land use/ land cover layer from satellite imageries (Tiwari and Khanduri 2011; Prakasam 2010). The land use/ land cover classes include forest cover, agricultural land, barren land, sand plain and water bodies.

\section{RESULTS AND DISCUSSION}

\section{Land use change in the watershed}

The total area of the Triyuga watershed considered for the study is $992 \mathrm{~km}^{2}$. The satellite imageries and corresponding land use land cover map of Triyuga watershed of years 1987, 1997, 2007 and 2015 is given in Fig. 3.

The classification results for the year 1987, 1997, 2007 and 2015 are shown in Table 2. The result show that the forest cover decreased significantly from $53.18 \%$ in 1987 to $30.19 \%$ in 1997 of the total area. The forest cover remained almost same $30.29 \%$ in 2007 but increased to $42.31 \%$ in 2015 . Day by day the forest cover area had been converted into barren land. The percentage of area covered by barren land increased from $10.98 \%$ in 1987 to $38.01 \%$ in 1997 but further the area of barren land decreased to $35.13 \%$ in 2007 and $19.17 \%$ in 2015. The forest cover area is also converted to agricultural land by few percentages. Total percentage of agricultural land increased from $24.65 \%$ in 1987 to $26.47 \%$ in 1997 and to $29.77 \%$ in 2007 and $30.23 \%$ in 2015 . The agricultural land is increasing continuously which is due to the increase in demand of the increasing population. The increase in the forest cover between the period 2007 and 2015 is due to introduction of the community forestry program.

\section{Water induced disaster as response to land use change}

The impacts of changing land use could have significant on flooding, erosion, and landslides. Therefore, land use can be considered as an important factor that significantly influences the landslide hazard condition in an area (Pathak 2014). The temporal distribution of various landuse classes at different periods show very high fluctuation on forest cover and barren land while the other classes are changed slightly (Fig. 4). In order to observe the relationship between land use and water induced disaster in the study area, the data on decadal disaster damage/loss has been evaluated (Table 3). 


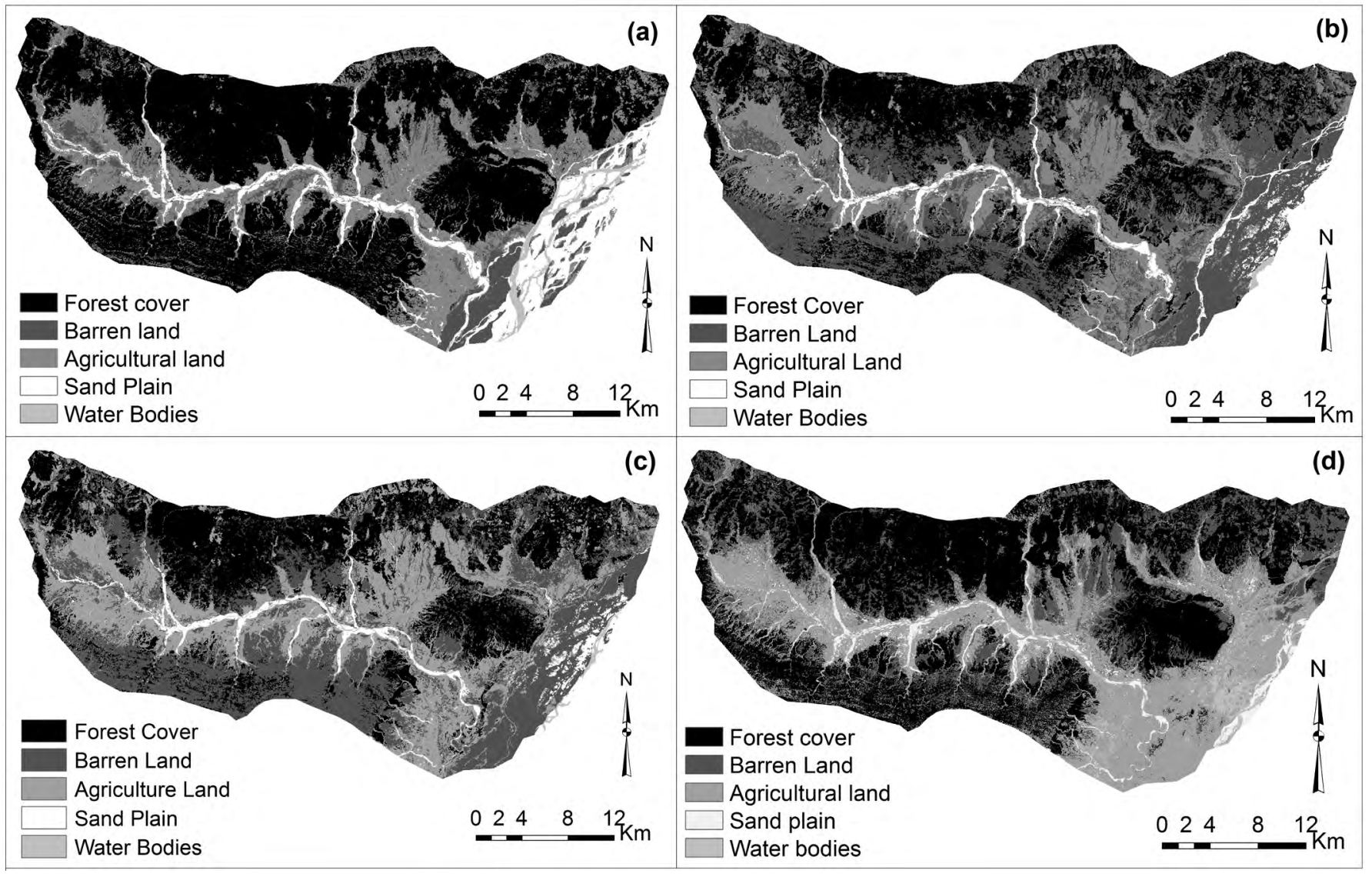

Fig. 3: Classified land use map for (a) 1987, (b) 1997, (c) 2007, and (d) 2015.

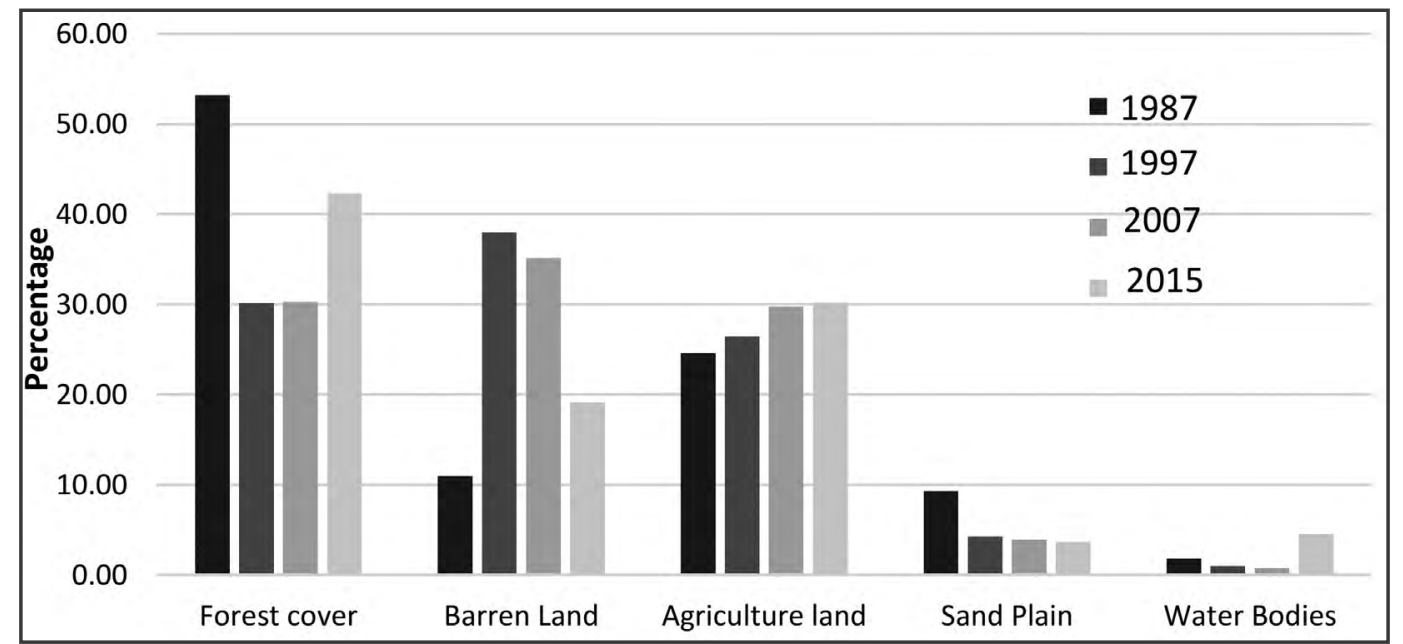

Fig. 4: Temporal distribution of various land use units within the watershed.

Table 2: Land use change pattern of different time period.

\begin{tabular}{|l|l|l|l|l|}
\hline Year & $\mathbf{1 9 8 7}$ & $\mathbf{1 9 9 7}$ & $\mathbf{2 0 0 7}$ & $\mathbf{2 0 1 5}$ \\
\hline Description & \% cover & \% cover & \% cover & \% cover \\
\hline Forest cover & 53.18 & 30.19 & 30.29 & 42.31 \\
\hline Barren Land & 10.98 & 38.01 & 35.13 & 19.17 \\
\hline Agriculture land & 24.65 & 26.47 & 29.77 & 30.23 \\
\hline Sand Plain & 9.28 & 4.25 & 3.95 & 3.67 \\
\hline Water Bodies & 1.83 & 1 & 0.78 & 4.55 \\
\hline
\end{tabular}


Land Use/Land Cover Change detection through temporal imageries and its implications in water induced disaster

Table 3: Water induced disaster losses in the Triyuga watershed.

\begin{tabular}{|l|l|l|l|l|l|l|l|l|}
\hline & \multicolumn{5}{|c|}{ Flood } & \multicolumn{5}{c|}{ Landslide } \\
\hline Period & Event Nos. & Deaths & $\begin{array}{l}\text { House } \\
\text { Destroyed }\end{array}$ & $\begin{array}{l}\text { Crops } \\
\text { Damaged } \\
\text { (Ha) }\end{array}$ & Event Nos. & Deaths & $\begin{array}{l}\text { House } \\
\text { Destroyed }\end{array}$ & $\begin{array}{l}\text { Crops } \\
\text { Damaged } \\
\text { (Ha) }\end{array}$ \\
\hline $1977-1987$ & 7 & 0 & 22 & 147.4 & 2 & 7 & 0 & 0 \\
\hline $1988-1997$ & 7 & 16 & 849 & 1464.7 & 1 & 6 & 1 & 17.6 \\
\hline $1998-2007$ & 60 & 24 & 122 & 113.9 & 27 & 22 & 70 & 1.4 \\
\hline $2008-2013$ & 48 & 13 & 43 & 1080.7 & 8 & 9 & 7 & 0 \\
\hline
\end{tabular}

(Source: UN/ISDR 2013)

Table 4: Monsoon precipitation ( $\mathrm{mm})$ in different time period.

\begin{tabular}{|l|l|l|l|l|l|l|l|l|}
\hline Period & Lahan & Gaighat & Udaypur Gadi & Barmajhiya & Dharan & Phatepur & Chatara & Basin Average \\
\hline $1987-1997$ & 3347.98 & N/A & 3331.95 & 4213.575 & 4958.08 & 2929.63 & 4329.55 & 3851.79 \\
\hline $1998-2007$ & 1291.3 & 1611.88 & 3291.825 & 3274.65 & 4197.48 & 3726.98 & 4174.1 & 3081.17 \\
\hline $2008-2014$ & 1275.35 & 931.525 & 1837.4 & 1698.45 & 2863.375 & 2709.55 & 2891.475 & 2029.59 \\
\hline
\end{tabular}

(Source: Department of Hydrology and Meteorology)

Comparison of land use/land cover change pattern with the disaster frequency and losses in the last four decade shows that the number of disastrous events and the resulting loss of lives and property is more in those decade where the forest cover area has decreased significantly. Any change in land use/ land cover is related with the hazard. During the period 1987 to 1997 , there is drastic decrease (almost $23 \%$ ) in forest cover area and at the same period, there is maximum damage to crop and household destruction by flood. Similarly, the destruction of crop by landslide is also maximum among all decades considered in the study.

\section{Water induced disaster events compared with precipitation}

The disaster loss is not only due to the change in landuse condition rather it is also due to direct impact of the rainfall magnitude. The losses due to water induced disaster (flood and landslide) event in the Triyuga watershed has been compared with the rainfall. The average rainfall for the summer season (from June to September) has been calculated for different stations in and around the Triyuga watershed (Table 4). The precipitation data earlier than 1987 was not available for the Triyuga watershed.

The data shows that the hazard occurrence is maximum in the period 1987 to 1997 . This is the period that has maximum amount of precipitation among the considered time periods (Table 4). This is also the period with highest disaster losses (Table 3). The amount of precipitation decreased in the period 1998 to 2007 and at the same period, the total loss or damage also decreased. But in period 2008 to 2014 the total area of the crop damaged due to hazard occurrence was increased even though there was significant decrease in the precipitation. It is due to the fact that in 2009 the Triyuga river swept away $507 \mathrm{Ha}$ of agricultural land which was the effect of continuous cutting of the river to the agricultural land since last 5 years, other VDCs were also affected due to this river (UN/ISDR 2013). The data indicates that there is good correlation between the disaster loss, landuse change and precipitation. However, the interpretation should be made carefully through considering various factors. In this case, the continuous effect of flooding during the monsoon season gradually weakened the river bank that collapsed even during low flood period.

\section{CONCLUSION}

The present study focuses on the land use/land cover change analysis in Triyuga watershed of east Nepal for the last four decades using temporal satellite imageries. The landuse change has been correlated with the disaster losses in the same period. The results show that the land use/land cover change was significant in the last four decades. The forest cover was decreased from 80's till 90's and 2000's, however the forest cover area increased moderately in 2010's and vice versa to barren land. The forest degradation resulting in the expansion of barren land adversely affected the soil erosion leading to significant loss during the period 1988-1997. The meteorological data also shows that there was maximum precipitation in the same period. Thus, the occurrence of disaster and the resulting losses can be compared with the changes in landuse and precipitation. The increased disaster loss at the later period (2008-2013) can be attributed to the fact that the disaster event occurred on 2009, which can be considered as a continuous effect of monsoon flooding that could have significant damage to the river bank even at low precipitation period, provided no mitigation measures (river training structures) are applied. Thus, many factors belonging to bio-physical and socio-economic factors contribute to land degradation. Likewise, climatic variability and change as well as inappropriate land use policies magnify the impacts of land degradation. 


\section{REFERENCES}

Bandyopadhyay, J., Mondal, I., and Roy, B., 2014, Change detection of land use and land cover and identification of inter-relationship between geomorphology and land use land cover in and around Bakkhali-fraserganj and Henry island, South 24 Parganas, West Bengal, India. International Jour. Remote Sensing and Geosci., v. 3(2), pp. 44-51.

Boriah, S., Kumar, V. Steinbach, M., Potter, C., and Klooster, S., 2008, Land cover change detection: a case study. Proceeding of the 14th ACM SIGKDD International Conference on Knowledge Discovery and Data Mining. pp. 857-865.

Briassoulis, H., 2000, Analysis of land use change-Theoretical and modelling approaches. Regional Research Institute, West Virginia University. Web book, available at http://www.rri.wvu. edu/webbook/briassoulis/contents.htm. Accessed on April 12, 2016.

GLCF (Global Land Cover Facility), 2004. Landsat technical guide, University of Maryland Institute for Advanced Computer Studies.

Holbrook, J. A. and Tudor, G. J., 1993, The use of remote sensing and GIS methods for mapping land cover change in Scotland, EARSel, Advances in Remote Sensing, v. 2(3), pp. 77-83.

Nori, W., Elsiddig, E. N, and Niemeyer, I., 2008, Detection of land cover changes using multi-temporal satellite imagery. The International Archives of the Photogrammetry, Remote Sensing and Spatial Information Sciences, v. 37, pp. 947-952.

Pathak, D., 2014, Water induced disaster in Tamor River sub-basin, east Nepal. DWIDP Bulletin, Series XV, pp. 6-11.
Prakasam, C., 2010, Land use and land cover change detection through remote sensing approach: A case study of Kodaikanal Taluk, Tamil Nadu. Int. Jour. Geomatics Geosci., v. 1(2), pp. 150-158.

Prawasi, R., Sharma, M. P., Babu, T. P., Saroj, O. P., Yadav, K., and Hooda, S., 2015, Land use and land cover mapping and change detection in Jind district of Haryana using multi-temporal satellite data, Int. Jour. Sci., Engr. Tech. Res., v. 4(5), pp. 15841588 .

Setiawan, Y. and Yoshino, K., 2012, Change detection in land use and land cover dynamics at a regional scale from Modis time series imagery. ISPRS Annals of the Photogrammetry, Remote Sensing and Spatial Information Sciences, v. I-7, pp. 243-248.

Singh, V. and Dubey, A., 2012, Land use mapping using remote sensing and GIS techniques in Naina-Gorma basin, part of Rewa district, M.P., India. International Journal of Emerging Technology and Advanced Engineering, v. 2(11), pp. 151-156.

Tiwari, K. and Khanduri, K., 2011, Landuse/landcover change detection in Doon Valley (Dehradun Tehsil), Uttarakhand: using GIS \& Remote Sensing Technique. International Jour. Geomatics and Geosci., v. 2(1), pp. 34-41.

UN/ISDR, 2004, Land use, disaster risk and rewards-A community leader's guide. UN/ISDR Africa Educational Series, v. 2(3), pp. $1-64$.

UN/ISDR, 2013, DesInventar-a free, open source Disaster Information Management System, UN/ISDR. (http://www.desinventar.net/ DesInventar/profiletab.jsp?countrycode $=\mathrm{npl}$ ). Accessed on March 15, 2016. 